\title{
Perfil dos tutores de cão e gato no município de Bom Jesus-PI
}

\author{
Dulcilany Pereira Cardoso ${ }^{1}$, Raylson Pereira de Oliveira ${ }^{2}$, Daiane de Sousa Estrela ${ }^{3}$, \\ Luana Araújo Saraiva ${ }^{4}$, Marcia Paula Oliveira Farias ${ }^{5}$, Pollyana Oliveira da Silva ${ }^{6}$
}

${ }^{I}$ Graduando em Medicina Veterinária pela Universidade Federal do Piauí, Campus professora Cinobelina Elvas, Departamento de Medicina Veterinária, Bom Jesus, Piauí, Brasil.E-mail: dulcy_pc@ hotmail.com

${ }^{2}$ Graduando em Medicina Veterinária pela Universidade Federal do Piauí, Campus professora Cinobelina Elvas, Departamento de Medicina Veterinária, Bom Jesus, Piauí, Brasil. E-mail: raylson.oliveira@ hotmail.com.br

${ }^{3}$ Graduando em Medicina Veterinária pela Universidade Federal do Piauí, Campus professora Cinobelina Elvas, Departamento de Medicina Veterinária, Bom Jesus, Piauí, Brasil. E-mail: Dayane-sousa-estrela@hotmail.com

${ }^{4}$ Médica Veterinária, Docente do Curso de Medicina Veterinária da Universidade Federal do Piauí, Campus professora Cinobelina Elvas, Departamento de Medicina Veterinária, Bom Jesus, Piauí, Brasil. E-mail: luanaaraujosaraiva@hotmail.com

${ }^{5}$ Médica Veterinária, Docente do Curso de Medicina Veterinária da Universidade Federal do Piauí, Campus professora Cinobelina Elvas, Departamento de Medicina Veterinária, Bom Jesus, Piauí, Brasil.E-mail: marciapbo@gmail.com

${ }^{6}$ Médica Veterinária, Docente do Curso de Zootecnia da Universidade Federal do Piauí, Campus professora Cinobelina Elvas, Departamento de Zootecnia, Bom Jesus, Piauí, Brasil. E-mail: pollyanaodasilva@ hotmail.com

RESUMO. Bom Jesus, no Piauí, é uma cidade na qual é visivelmente notável uma grande quantidade de animais errante circulando pelas ruas. A pesquisa objetivou-se caracterizar o perfil de tutores de cães e gatos do município, levando em consideração o comportamento quanto a posse responsável desses animais. A caracterização dos tutores foi feita pela aplicação de questionários com 25 perguntas objetivas, dentre elas perguntas socioeconômicas e sobre cuidados que devem ser tomados com o animal de estimação. A cidade de Bom Jesus demonstrou ser uma cidade em que a população na sua maioria possui curso superior completo ou a concluir e economicamente de classe média. Mas mesmo assim não obteve bons resultados com relação a posse responsável, pois $19,57 \%$ dos animais tem acesso livre a rua, $18,92 \%$ saem para passear sem guia ou desacompanhados, desses apenas $11,1 \%$ recolhem as fezes de seus animais na rua, $38,60 \%$ nunca foram levados ao médico veterinário, $64 \%$ relataram que o animal já teve infestação por ectoparasitos e desses apenas 9,09 foi tratado de forma correta (animal e ambiente) e na sua minoria 19,3\% não faz utilização de antihelmíntico regularmente. Com o presente trabalho foi possível concluir que a maioria dos entrevistados não toma o devido cuidado com seus animais, demonstrando que a cidade de Bom Jesus precisa urgentemente de um programa de conscientização da população sobre guarda responsável de seus animais e dos riscos de zoonoses.

Palavras-Chave: bem estar, guarda responsável, zoonoses.

\section{Guardian's profile of dogs and cats in Bom Jesus-PI}

ABSTRACT. Bom Jesus, Piaui, is a city in which is visibly noticeable a lot of errant
animals roaming the streets. The study aimed to characterize the profile of dog and cat
guardians of the city, taking into account the behavior and responsible ownership of these
animals. The characterization of the tutors was made through the use of questionnaires
with 25 objective questions, among them socio-economic questions and on care to be
taken with the pet. The city of Bom Jesus proved to be a city where the population mostly
has a college degree or complete and economically middle class. But still did not get
good results with respect to responsible ownership, as $19.57 \%$ of the animals have free
access to the street, $18.92 \%$ go out to walk without a guide or unaccompanied, only
$11.11 \%$ of those collect the feces of their animals on the street, 38.60\% were never taken
to the veterinarian, $64 \%$ reported that the animal had already infestation by ectoparasites
and of these only 9.09 was treated correctly (animal and environment) and its $19.30 \%$ 
minority not Any use of anthelmintic regularly. With this study it was concluded that the majority of respondents do not take proper care of their animals, showing that the city of Bom Jesus urgently needs a public awareness program on responsible custody of their animals and zoonosis risks.

Keywords: Welfare, responsibility guard, zoonosis

\section{Introdução}

$\mathrm{O}$ aquecimento no mercado pet shop vem sendo ocasionado pela diminuição das estruturas familiares e pelo aumente de pessoas que residem sozinhas, levando-as a buscarem nos animais uma companhia para o seu dia a dia (Afonso et al., 2008). Estudos também demonstram que cães e gatos estão deixando de ser apenas uma companhia e passando a ser considerados membros da família (Lancendorfer et al., 2008). Apesar de muitos tutores terem essa consideração com seus animais, ainda existem aqueles que insistem em maltratá-los e abandoná-los (Matos et al., 2012).

Pessoas que convivem com animais de forma saudável tem menos histórico de depressão, estresse, mau humor, melhorando a qualidade de vida de idosos, crianças e pessoas deficientes (Babá et al., 2015). A zooterapia (tratamento com utilização de animais) vem sendo utilizada como forma de auxílio no tratamento de crianças que foram vítimas de violência, seja ela física ou psíquica, minimizando o seutrauma sofrido, além do uso em idosos e pessoas com deficiência, física ou mental, o que tem levado a resultados satisfatórios (Porto \& Cassol, 2007).

Entretanto, pelo fato dos animais estarem envolvidos involuntariamente na transmissão de mais de 60 infecções zoonóticas (Macpherson, 2005) e constituir uma importante fonte de infecção por parasitas, bactérias, fungos e vírus (Geffray, 1999, Plaut et al., 1996), todos os benefícios da convivência (animal/tutor) podem ser perdidos se a saúde desses animais não for tida com maiores cuidados (Katagiri \& OliveiraSequeira, 2007).

O município de Bom Jesus-PI não conta com o apoio de um centro de controle de zoonoses (CCZ) local, instituição pública altamente necessária para controle de doenças e animais errantes. Sendo que o CCZ mais próximo encontra-se na cidade de Floriano-PI, há 400 km de distância. O CCZ é uma instituição municipal, geralmente vinculada à secretaria municipal de saúde, que tem o objetivo e dever legal de cuidar e fazer o controle das zoonoses e da

superpopulação de animais domésticos errantes (Babá et al., 2015).

Por falta dessa instituição e, provavelmente por descuido evidente de seus tutores, é possível notar nesse município uma grande quantidade de animais peridomiciliados, andando livremente pelas ruas, sem coleira e visivelmente maltratados. Os animais errantes são fruto da falta de cuidado de alguns proprietários que abandonam seus animais nas ruas, os quais passam a se reproduzir dando origem a proles que também serão errantes, gerando dessa forma um grande problema a sociedade (Silva et al., 2009). Para ter a guarda de um animal de estimação o proprietário precisa estar consciente das suas responsabilidades para com o animal como vacinação, alimentação, castração, higiene, segurança e moradia (Santana \& Oliveira, 2006), ou seja, garantir que o animal tenha condições ideais de sobrevivência.

Diante do contexto apresentado, desenvolveuse este estudo com o objetivo caracterizar o perfil de tutores de cães e gatos do município de Bom Jesus-PI, levando em consideração o comportamento quanto a posse responsável desses animais.

\section{Material e Métodos}

A presente pesquisa foi realizada na cidade de Bom Jesus, localizada no sul do estado do Piauí distante $635 \mathrm{~km}$ da capital Teresina, com uma população de 22.629 habitantes e uma área de $5.469,181 \mathrm{~km}^{2}$ (IBGE, 2015).

A pesquisa constituiu-se na aplicação de questionários com perguntas objetivas, dentre elas, perguntas socioeconômicas e as outras sobre cuidados que devem ser tomados com o animal de estimação. A amostragem foi definida de forma inteiramente ao acaso, sendo que foram visitados 3 (três) bairros (São Pedro, Alto Alegre e Centro), de um total de 9 bairros do município. Dos domicílios visitados apenas aqueles que continham cães e/ou gatos tiveram seus responsáveis entrevistados por meio de questionários, resultando em 57 amostras. As 
questões foram respondidas por apenas pelo responsável domiciliar no momento da pesquisa. As variáveis independentes foram grau de escolaridade do proprietário da casa e renda familiar (Soma de todos os rendimentos da família).

As respostas aos questionamentos foram distribuídas em frequências, sendo os resultados apresentados em forma de percentagem. Levando em consideração as seguintes variáveis dependentes: Quantidade de animais de companhia no domicilio; objetivo da criação; Local de permanência do animal; Acompanhamento dos animais durante passeios; Atitude do responsável com relação as fezes do seu animal na rua; No último mês quantas vezes deram banho no cachorro e/ou gato; Possui algum animal que tenha sido castrado? Quantos?; Quem foi o profissional que fez a castração?; Quando o seu animal tem cria, o que faz com os filhotes; Quais vacinas o animal já tomou?; Já levou para consultar no veterinário?; Já fez algum exame para calazar (leishimania), se positivo, qual foi a instituição ou laboratório?; Já teve infestação ou presença de ectoparasitos? fez tratamento?; Já tratou o ambiente domiciliar contra esses ectoparasitas?; O animal já fez utilização de antihelmíntico (vermifugação)?; Em que local o animal costuma fazer as suas necessidades fisiológicas (cocô e urina)?; Os animais sofre de algum tipo de patologia (doença), qual?; Quanto a essa patologia o animal foi tratado?; Se o tutor já possuiu outros animais e porque não os tem mais?; e se já teve algum caso de pessoas na residência com alguma doença transmitida por animais, ou suspeita?
Durante o desenvolvimento das entrevistas foi realizado pelos entrevistadores um prévio esclarecimento, aos entrevistados, sobre os questionamentos propostos, lhes garantindo o direito a não participação e o sigilo em relação à sua identidade.

\section{Resultados e Discussão}

Durante a execução do trabalho não se obteve nenhuma perda de dados ou recusa, por meio dos entrevistados, diante de qualquer dos questionamentos. Dos 57 tutores envolvidos no estudo, 66,7\% são responsáveis por caninos e $19,3 \%$ por felinos. Sendo que desses percentuais, $14,0 \%$ tinha a guarda de cães e gatos simultaneamente. A alta prevalência pela criação de animais da espécie canina observada no presente estudo demonstra um costume que vem sendo seguido a muitos anos, sendo o cão considerado um dos animais domésticos de convivência mais antiga, datada há mais de dez mil anos (Dotson \& Hyatt, 2008), pois além da sua companhia são responsáveis pela segurança do domicilio.

Quanto ao aspecto de escolaridade dos tutores analisados na pesquisa $24,6 \%$ possuíam ensino médio completo e $42,1 \%$ já concluíram ou estão cursando o ensino superior (Tabela 1). Apenas $3,5 \%$ não tinham nem um grau de escolaridade. Considerando os bairros visitados, o centro foi o que apresentou o maior grau de escolaridade com $52,94 \%$ dos proprietários com curso superior completo ou cursando o ensino superior.

Tabela 1. Frequência relativa do grau de escolaridade dos proprietários de animais em diferentes bairros de Bom Jesus-PI

\begin{tabular}{lc}
\hline Escolaridade & Percentagem $(\%)$ \\
\hline Sem grau de escolaridade & 3,51 \\
Ensino fundamental incompleto & 8,77 \\
Ensino fundamental completo & 7,02 \\
Ensino médio incompleto & 24,56 \\
Ensino médio completo & 12,28 \\
Ensino superior incompleto & 21,05 \\
Ensino superior completo & 21,05 \\
Não souberam responder & 1,75 \\
\hline Total & 100 \\
\hline
\end{tabular}


Ao se analisar a justificativa para criação dos animais foi verificado no presente estudo que $66,7 \%$ era para companhia e $26,3 \%$ para segurança. Demonstrando assim que os tutores desses animais devem ter uma atenção especial para com eles, pois estão em maior contato com os seres humanos e devido a essa aproximação podem transmitir alguma zoonose ou causar um acidente. Segundo Pinheiro Júnior et al. (2006) os animais criados com a finalidade de companhia recebem uma melhor atenção de seus proprietários, o que não foi observado no município de Bom Jesus, como veremos a seguir, visto muitos animais não recebiam se quer os cuidados básicos.
Com relação à forma de criação o estudo revelou que $32,6 \%$ dos cães possui livre acesso a área interna do domicilio, enquanto 30,43\% permanecem apenas na área externa, observou-se ainda que $19,57 \%$ dos animais tinham livre acesso à rua (Tabela 2). $\mathrm{O}$ bairro centro foi o que apresentou a maior quantidade de animais criados no peridomicilio com $42,9 \%$.

Analisando a forma de criação dos gatos observou-se que $26,9 \%$ dos animais encontrados nos domicílios pesquisados são criados permanentemente soltos, com total liberdade para sair da casa.

Tabela 2. Frequência relativa da forma de criação dos cães no município de Bom Jesus-PI

\begin{tabular}{lc}
\hline Criação & Percentagem \% \\
\hline Acesso à área interna do domicilio & 32,61 \\
Solto na área externa do domicilio & 30,43 \\
Preso na corrente & 15,22 \\
Acesso livre a rua & 19,57 \\
Preso no canil & 2,17 \\
\hline Total & 100 \\
\hline
\end{tabular}

Dos animais que permanecem dentro das residências 78,4\% saem para passear acompanhados de seus responsáveis e com utilização de guia, $10,8 \%$ saem para passear acompanhados, mas sem a guia, $8,1 \%$ saem desacompanhados e 2,7\% não saem para passear. Além do bem estar do animal, o passeio é de extrema importância para diminuir o estresse de ficar preso por longos períodos, no entanto esse deve ser feito acompanhado e com auxílio de guia e se preciso focinheira, para evitar possíveis agressões a humanos e outros animais. Se uma pessoa for agredida por um cão, ou outro animal, ela deve procurar imediatamente uma unidade de saúde, mesmo que o ferimento não seja grave, pois pode haver a possibilidade de infecções bacterianas e em caso mais grave do vírus da raiva.

Dos entrevistados que afirmam acompanhar os seus animais durante o passeio, $58,3 \%$ disseram que nem sempre recolhem as fezes dos seus animais das ruas, sendo apenas $11,11 \%$ acompanhantes que sempre recolhem. As fezes dos animais domésticos são uma importante fonte de infecção, pois podem contaminar grandes áreas, podendo infectar outros animais e o homem (Blazius et al., 2005, Capuano \& Rocha, 2006).

Com relação aos banhos, $34,8 \%$ dos entrevistados de casas que possuíam cães, relatou que no último mês deram banho no animal uma única vez e em segundo lugar ficou o banho semanal com 26,1\%. Ainda se observou um índice de $15,2 \%$ de animais que não tomaram banho (Tabela 3). Os gatos em sua maioria $57,89 \%$ dos animais não tomam banho. Para manter uma boa sanidade e diminuir o estresse térmico no animal, o ideal é dar banho a cada 7 (sete) dias no verão e a cada 15 (quinze) no inverno, sendo que dar banho no animal todos os dias o deixa vulnerável a infecções, a não ser que esse animal esteja em tratamento de alguma doença de pele.

Dos 57 domicílios visitados, apenas em 22, $8 \%$ havia animais castrados, sendo 11 cães e 5 gatos, e todos castrados por um Médico veterinário. Dos 62 animais que não são castrados 11 tem suas crias destinadas a doação, 5 para venda e dois não souberam responder, sendo os outros 44 divididos eram machos e filhotes. O controle reprodutivo de cães e gatos é fator extremamente importante em saúde pública, 
diminuído dessa maneira a população de animais errantes (Soto et al., 2006). Esse controle também ajuda a diminuir incidência de acidentes com cães, principalmente mordeduras, acidentes de trânsito (Loss et al., 2012), além de evitar doenças como neoplasias testiculares e ovarianas (Rand \& Hanlon, 2008), desordens reprodutivas, neoplasias mamárias, piometra (Kustritz, 2007), 2007), vírus da imunodeficiência felina (FIV) e da leucemia felina (FeLV).

Tabela 3. Resultado do questionamento sobre a frequência com a qual o proprietário deu banho no seu cão no último mês.

\begin{tabular}{lc}
\hline Banhos & Percentagem \% \\
\hline Uma vez & 34,78 \\
Duas vezes & 21,74 \\
Todas as semanas & 26,09 \\
Todos os dias & 2,17 \\
Nunca deu banho & 15,22 \\
\hline Total & 100 \\
\hline
\end{tabular}

Com relação ao acompanhamento desses animais por Médico Veterinário, foi constatado que apenas $12,3 \%$ dos animais são levados no médico veterinário regularmente, $49,12 \%$ só são levados quando estão doentes e 38,60\% nunca foram levados ao Médico Veterinário. O que é um fator extremamente preocupante para a saúde tanto do animal quanto do proprietário, pois nos acompanhamentos feitos pelo médico veterinário o proprietário recebe orientações dos cuidados que devem ser tomados, da importância de seguir o calendário de vacina e os procedimentos que precisem ser realizados no caso do diagnóstico de alguma patologia (Gazzano et al., 2008).

No que se refere à vacinação $91,2 \%$ dos animais da pesquisa recebem vacina anti-rábica, o que é considerado um bom resultado, visto que o Ministério da Saúde preconiza uma cobertura vacinal de no mínimo 70\% (Ministério da Saúde, 2007). Desses $91,2 \%$ vacinados, $49,1 \%$ recebe apenas a vacina anti-rábica. Demonstrando haver uma falta de esclarecimento dos proprietários sobre o calendário de vacinação animal e que só a vacina anti-rábica não protege ele de todas as doenças, inclusive algumas zoonoses. Esclarecimento esse que os proprietários receberiam se levassem seus animais ao médico veterinário. A vacinação feita em casas agropecuárias é outro fator preocupante, pois muitas vezes essas vacinas não são armazenadas em local adequado, e a pessoa responsável pela venda nem sempre tem o conhecimento necessário de todo o programa de vacina que deve ser realizado no animal, principalmente quando filhote (Langoni et al., 2011).
A infestação por ectoparasitas foi outro resultado preocupante, pois $64 \%$ relataram que o animal já teve infestação, sendo que $73,0 \%$ por carrapato, $18,9 \%$ por pulgas e $8,1 \%$ por ambos os parasitas. Dos animais que já tiveram infestação por ectoparasitas $36,8 \%$ foram tratados por médico veterinário, $28,9 \%$ teve medicamento indicado por um prático, em 18,4\% dos animais o proprietário fez o tratamento por conta própria, e 15,8\% outras respostas (Tabela 4). Em apenas $9,1 \%$ dos domicílios foi feito tratamento correto, sendo tratado o ambiente quando os animais estavam em tratamento, na sua maioria 50,91\% nunca tratou o ambiente. Os ectoparasitas são muito comuns principalmente em comunidades carentes no Brasil, e mesmo assim são negligenciados pelos proprietários, profissionais da área e pelas autoridades de saúde (Heukelbach et al., 2003).

Outro dado preocupante é com relação a utilização de antihelmíntico, pois em primeiro lugar com 29,82\% encontram-se entrevistados que relatam nunca ter feito tratamento nos animais (Tabela 5), sendo que 19,30\% a faz regularmente. Dos animais que fazem suas necessidades fisiológicas dentro do domicilio, apenas um recebia antihelmíntico regularmente. Medidas profiláticas incluindo a utilização de antihelmíntico são indispensáveis aos animais e homens, para que estes fiquem imunes a diversas enfermidades, incluindo zoonoses (WHO, 2005), que representam um sério risco à saúde pública, como, por exemplo, a transmissão das larvas migrans cutânea e visceral (Langoni et al., 2011). 
Tabela 4. Resultado do questionamento sobre tratamento dos animais acometidos por ectoparasitas.

\begin{tabular}{|c|c|}
\hline Tratamento & Percentagem $\%$ \\
\hline Medicamento indicado por médico veterinário & 36,84 \\
\hline Medicamento indicado por pratico & 28,95 \\
\hline Remédio caseiro & 10,53 \\
\hline Tratamento por conta própria & 18,42 \\
\hline Não tratou & 5,26 \\
\hline Total & 100 \\
\hline $\begin{array}{l}\text { Dentre as zoonoses de conhecimento dos } \\
\text { entrevistados a larva migrans cutânea foi a de } \\
\text { maior relato de contaminação, } 4 \text { (quatro) pessoas } \\
\text { acometidas, seguida pela sarna com } 3 \text { (três) } \\
\text { pessoas e tunguiase com } 2 \text { (duas). Dos } \\
\text { entrevistados } 3 \text { (três) pessoas não souberam } \\
\text { responder, provavelmente por não saber do que } \\
\text { se trata. Todos os proprietários que relataram } \\
\text { algum tipo de zoonose nunca levaram os seus } \\
\text { animais ao Médico Veterinário, não fazem } \\
\text { tratamento do ambiente contra ectoparasitas e } \\
\text { nunca deram antihelmíntico ou só administraram } \\
\text { uma única vez. }\end{array}$ & $\begin{array}{l}\text { Com o resultado dessa pesquisa, pode-se } \\
\text { observar que a população Bom Jesuense, na sua } \\
\text { maioria, não dar a devida atenção aos seus } \\
\text { animais de estimação. Não sendo esse um } \\
\text { problema restrito ao município de Bom Jesus-PI; } \\
\text { sendo também observado por Langoni et al. } \\
\text { (2011) no município de Botucatu. Demonstrando } \\
\text { que o município de Bom Jesus precisa } \\
\text { urgentemente de um Centro de controle de } \\
\text { zoonoses, para cuidar das prováveis doenças, e da } \\
\text { grande quantidade de animais nas ruas, além de } \\
\text { um programa educativo para a população, sobre } \\
\text { guarda responsável de seus animais e dos riscos } \\
\text { de zoonoses. }\end{array}$ \\
\hline Vermifugação & Percentagem $\%$ \\
\hline A cada três meses & 19,30 \\
\hline Uma única vez & 19,30 \\
\hline Quando filhote & 29,82 \\
\hline Nunca foi desvermifugado & 29,82 \\
\hline Não soube responder & 1,75 \\
\hline Total & 100 \\
\hline
\end{tabular}

\section{Conclusões}

Com o presente trabalho foi possível concluir que a maioria dos entrevistados no município de Bom Jesus, apesar de possuírem um bom grau de escolaridade, não possui informações suficientes sobre as formas corretas de cuidar de seus animais de estimação. Não sendo feitos os procedimentos básicos como: castração, utilização de antihelmíntico, controle de ectoparasitas e sendo observada uma grande quantidade de animais peridomiciliados.

\section{Referências Bibliográficas}

Afonso, T., Berdasco, L., Medeiros, T. \& Rejowski, M. (2008). Mercado pet em ascensão-hotelaria para cães e gatos em São Paulo (Brasil). Revista Brasileira de Pesquisa em Turismo, 2, 102-123.

Babá, A. Y., Obara, A. T. \& Silva, E. S. (2015). Levantamento do conhecimento de proprietários de cães domésticos sobre zoonoses. UNOPAR - Científica Ciências Humanas e Educação, 14, 251-258.

Blazius, R. D., Emerick, S., Prophiro, J. S., Romão, P. R. T. \& Silva, O. S. (2005). Ocorrência de protozoários e helmintos em amostras de fezes de cães errantes da cidade de Itapema, Santa Catarina. Revista da Sociedade Brasileira de Medicina Tropical, 38, 73-74. 
Capuano, D. M. \& Rocha, G. M. (2006). Ocorrência de parasitas com potencial zoonótico em fezes de cães coletadas em áreas públicas do município de Ribeirão Preto, SP, Brasil. Revista Brasileira de Epidemiologia, 9, 81-86.

Dotson, M. J. \& Hyatt, E. M. (2008). Understanding dog-human companionship. Journal of Business Research, 61, 457-466.

Gazzano, A., Mariti, C., Alvares, S., Cozzi, A., Tognetti, R. \& Sighieri, C. (2008). A prevenção de comportamentos indesejáveis em cães: eficácia da veterinária conselhos dado a donos de cachorro. Journal of Veterinary Behavior, 3, 125-133.

Geffray, L. (1999). [Infections associated with pets]. La Revue de Medicine Interne, 20, 888901.

Heukelbach, J., Oliveira, F. A. S. \& Feldmeier, H. (2003). Ectoparasitoses e saúde pública no Brasil: desafios para controle Ecoparasitoses and public health in Brazil: challenges for control. Caderno de Saúde Pública, 19, 15351540 .

Katagiri, S. \& Oliveira-Sequeira, T. C. G. (2007). Zoonoses causadas por parasitas intestinais de cães e o problema do diagnóstico. Arquivos do Instituto Biologico, 74, 175-84.

Kustritz, M. V. R. (2007). Determining the optimal age for gonadectomy of dogs and cats. Journal of the American Veterinary Medical Association, 231, 1665-1675.

Lancendorfer, K. M., Atkin, J. L. \& Reece, B. B. (2008). Animals in advertising: Love dogs? Love the ad! Journal of Business Research, 61, 384-391.

Langoni, H., Troncarelli, M. Z., Rodrigues, E. C., Nunes, H. R. d. C., Harumi, V., Henriques, M. V., Silva, K. M. \& Shimono, J. Y. (2011). Conhecimento da população de Botucatu-SP sobre guarda responsável de cães e gatos. Veterinária e Zootecnia, 18, 297-305.

Loss, L. D., Mussi, J. M. S., Mello, I. N. K., Leão, M. S. \& Franque, M. P. (2012). Posse responsável e conduta de proprietários de cães no município de Alegre-ES. Acta Veterinaria Brasilica, 6, 105-111.

Macpherson, C. N. L. (2005). Human behaviour and the epidemiology of parasitic zoonoses.
International Journal for Parasitology, 35, 1319-1331.

Matos, L. V. S., Teixeira, W. F. P., Aquino, M., Viol, M. \& Bresciani, K. D. S. (2012). Orientação sobre posse responsável em uma área endêmica para Leishmaniose Visceral Canina. Revista Ciência em Extensão, 8, 3441.

Pinheiro Júnior, O. A., Ssilva, M. O. C., Angela, H. L., Tozzetti, D. S. \& Segura, R. (2006). Posse responsável de cães e gatos no município de Garça/SP. Revista Científica Eletronica de Medicina Veterinária, 3, 1-4.

Plaut, M., Zimmerman, E. M. \& Goldstein, R. A. (1996). Health hazards to humans associated with domesticated pets. Annual Review of Public Health, 17, 221-245.

Porto, R. T. C. \& Cassol, S. (2007). Zooterapia uma lição de cidadania: o cão sociabilizador e a criança vítima de violência intrafamiliar. Discurso Jurídico, 3, 46-74.

Rand, J. S. \& Hanlon, C. (2008). Report on the validity and usefulness of early age desexing in dogs and cats. Department of Primary Industries and Fisheries, 1, 1-5.

Santana, L. R. \& Oliveira, T. P. (2006). Guarda responsável e dignidade dos animais. Revista Brasileira de Direito Animal, 1, 207-230.

Silva, F. A. N., Carvalho, R. L., Klein, R. P. \& Quessada, A. M. (2009). Posse responsável de cães no bairro Buenos Aires na cidade de Teresina (PI). Ars Veterinaria, 25, 14-17.

Soto, F. R. M., Ferreira, F., Pinheiro, S. R., Nogari, F., Risseto, M. R., Souza, O. \& Amaku, M. (2006). Dinâmica populacional canina no Município de Ibiúna-SP: estudo retrospectivo. Brazilian Journal of Veterinary Research and Animal Science, 43, 178-185.

WHO. (2005). World health organization. The comtrol of neglected zoonotic diseases. WHO technical report series.

\section{Article History:}

Received 25 April, 2016

Accepted 17 May, 2016

Available online 25 June, 2016

License information: This is an open-access article distributed under the terms of the Creative Commons Attribution License, which permits unrestricted use, distribution, and reproduction in any medium, provided the original work is properly cited. 